were recorded before and after receiving transfusion. BP was measured using standard noninvasive oscillometric technique before performing every echocardiographic assessment. A single investigator using Philips HD-11 machine performed the haemodynamic assessments utilising standard echocardiographic and Doppler techniques. Ethics approval was obtained \& statistical analysis performed utilising SPSS17.0 software.

Results: Complete data on 288 measurements was available for analysis(Table 1). The mean gestation of study infants was 26 weeks and birth weight 863 gram. Of these, $70 \%$ infants were on respiratory support at the time of study.

Table1: Pearson's correlation coefficient comparing variables $\left({ }^{*} p<0.01\right)$

\begin{tabular}{|l|l|l|l|l|l|l|}
\hline & LVCO & RVO & $\begin{array}{l}\text { SVC } \\
\text { FLOW }\end{array}$ & $\begin{array}{l}\text { SYS- } \\
\text { TOLIC } \\
\text { BP }\end{array}$ & $\begin{array}{l}\text { MEAN } \\
\text { BP }\end{array}$ & $\begin{array}{l}\text { DIAS- } \\
\text { TOLIC } \\
\text { BP }\end{array}$ \\
\hline LVCO & 1 & $.494^{*}$ & $.508^{*}$ & .236 & .124 & -.006 \\
\hline RVO & $.494^{*}$ & 1 & $.477^{*}$ & .196 & .187 & .132 \\
\hline $\begin{array}{l}\text { SVC } \\
\text { FLOW }\end{array}$ & $.508^{*}$ & $.477^{*}$ & 1 & $.417^{*}$ & .267 & .123 \\
\hline $\begin{array}{l}\text { SYS- } \\
\text { TOLIC } \\
\text { BP }\end{array}$ & .236 & .196 & $.417^{*}$ & 1 & $.809^{*}$ & $.653^{*}$ \\
\hline $\begin{array}{l}\text { MEAN } \\
\text { BP }\end{array}$ & .124 & .187 & .267 & $.809^{*}$ & 1 & $.898^{*}$ \\
\hline $\begin{array}{l}\text { DIAS- } \\
\text { TOLIC } \\
\text { BP }\end{array}$ & -.006 & .132 & .123 & $.653^{*}$ & $.898^{*}$ & 1 \\
\hline
\end{tabular}

[Table 1: Pearson's correlation coefficient compari]

Conclusions: Systolic BP has significant correlation with SVC flow, and a significant positive correlation exists between SVC flow, LVCO \& RVO. There is no correlation between mean BP and SVC flow, LVO or RVO.

${ }^{1}$ ADC F\&N2007;92(suppl1):A39-A41

\section{CARDIOPROTECTIVE EFFECTS OF CYCLOSPORINE IN A NEWBORN PIGLET MODEL OF ASPHYXIA: A DOSE-RESPONSE STUDY}

\section{R. Gill'1, N. Manouchehri', J.-Q. Liu'², T.-F. Lee², D. Bigam 1 , P.-Y. Cheung ${ }^{2}$ \\ ${ }^{1}$ Surgery, ${ }^{2}$ Pediatrics, University of Alberta, Edmonton, $A B$, Canada}

Introduction: Myocardial depression following asphyxia of the newborn is a significant cause of mortality. Cyclosporine reduces myocardial damage in adult patients undergoing percutaneous coronary intervention for myocardial infarction. However, the potential cardioprotective effects of cyclosporine in neonates have not yet been studied. We hypothesize that cyclosporine in asphyxiated newborn piglets will improve cardiac function, systemic hemodynamics and oxygen metabolism.

Methods: Thirty-six piglets (1-4 days-old) were instrumented for continuous monitoring of cardiac output and systemic arterial pressures. After stabilization, normocapnic alveolar hypoxia (10$15 \%$ oxygen) was instituted for $2 \mathrm{~h}$ followed by reoxygenation with $100 \%$ oxygen for $0.5 \mathrm{~h}$, then $21 \%$ for $3.5 \mathrm{~h}$. Piglets were block randomized to receive one of three cyclosporine intravenous boluses $(2.5$, 10 or $25 \mathrm{mg} / \mathrm{kg}$ ) or placebo (normal saline, control) after 5 minutes of $100 \%$ reoxygenation ( $n=8 /$ group). Blood samples were collected for analysis of blood gases and plasma troponin. Statistical analysis performed using ANOVA.

Results: All piglets demonstrated cardiogenic shock (cardiac output $45 \%$ of baseline), hypotension (systemic arterial pressure $30 \mathrm{mmHg}$ ) and acidosis $(\mathrm{pH}=7.04)$ at the end of $2 \mathrm{~h}$ of hypoxia. Cyclosporine treatment at reoxygenation caused dose-related improvements in cardiac output and oxygen delivery compared to controls (both $\mathrm{P}<0.05$ ). Cyclosporine at $10 \mathrm{mg} / \mathrm{kg}$ significantly improved stroke volume compared to controls, demonstrating preservation of cardiac function. Plasma troponin, a marker of myocardial damage, was significantly higher in controls than that of 2.5 and $10 \mathrm{mg} / \mathrm{kg}$ cyclosporine treatment groups.

Conclusion: We first demonstrated that the postresuscitation administration of cyclosporine caused dose-related preservation of cardiac function in newborn piglets following asphyxia-reoxygenation. 